\title{
Distribution of subfossil chironomids (Diptera, Chironomidae) along a water depth gradient in the shallow Lake Spore, northern Poland
}

\author{
Krzysztof PLESKOT, ${ }^{1,2^{*}}$ Mónika TÓTH, ${ }^{3}$ Karina APOLINARSKA ${ }^{4}$
}

${ }^{1}$ Laboratory of Wetland Ecology and Monitoring, Faculty of Geographical and Geological Sciences, Adam Mickiewicz University in Poznań, Krygowskiego 10, 61-680 Poznań, Poland; ${ }^{2}$ Department of Biogeography and Palaeoecology, Faculty of Geographical and Geological Sciences, Adam Mickiewicz University in Poznań, Krygowskiego 10, 61-680 Poznań, Poland; ${ }^{3}$ Balaton Limnological Institute, MTA Centre for Ecological Research, Klebelsberg Kuno 3, 8237 Tihany, Hungary; ${ }^{4}$ Institute of Geology, Faculty of Geographical and Geological Sciences, Adam Mickiewicz University in Poznań, Krygowskiego 12, 61-680 Poznań, Poland

\begin{abstract}
Subfossil chironomid (Diptera, Chironomidae) remains are often used as indicators of lake level changes in palaeolimnological studies. However, their usefulness as a water depth proxy can vary between the sites, depending on the lake morphology, mode of taphonomic processes or amplitude of past water level fluctuations, among other factors. In this study, we have examined the distribution of subfossil chironomids in the shallow Lake Spore (northern Poland) to assess the influence of water depth on the fauna. Our aim was to evaluate the site-specific utility of subfossil chironomids for lake level reconstruction at Lake Spore. The subfossil chironomid assemblages in Lake Spore have heterogeneous distribution, suggesting they are predominately composed of remains deposited close to the sampling location. A strong relationship between the water depth and the chironomids is marked by the $25.12 \%$ variance explained by water depth in the taxonomic data. Moreover, according to generalized linear models (GLMs) out of 44 dominant taxa, 12 have significant relationships with water depth. However, the sensitivity of our chironomid fauna to water depth changes is not continuous along the entire depth gradient. The most abrupt assemblage change occurs at 2.6-3.7 $\mathrm{m}$ water depth, in proximity to the depth where macrophytes become less dense and finally disappear. We conclude that, despite these strong chironomid-water depth relationships, only major water level fluctuations can be satisfactorily reconstructed due to the limited turnover rates of the fauna along a depth gradient and relatively small amplitude of the lake level variations characteristic for East-Central Europe.
\end{abstract}

\section{INTRODUCTION}

Lake water-level changes can be driven by different factors, including climate, tectonics, beaver dams, vegetation changes or human activity (Dearing, 1997; Gałka and Apolinarska, 2014; Dietze et al., 2016). Such occurrences markedly affect the whole lake ecosystem, which is particularly true for shallow lakes (Coops et al., 2003). Thus, an understanding of long-term lacustrine ecosystem dynamics requires proper knowledge on

\section{Corresponding author: krzysztofpleskot@gmail.com}

Key words: Non-biting midges; lake level; palaeohydrology; environmental changes.

Edited by: Valeria Lencioni, MUSE-Museo delle Scienze, Trento, Italy.

Received: 13 May 2019.

Accepted: 22 July 2019.

This work is licensed under a Creative Commons Attribution NonCommercial 4.0 License (CC BY-NC 4.0).

${ }^{\circ}$ Copyright: the Author(s), 2019

Licensee PAGEPress, Italy

J. Limnol., 2019; 78(3): 336-347

DOI: 10.4081/jlimnol.2019.1916 concurrent lake level fluctuations. In palaeolimnological studies, this knowledge is derived from different geochemical and biotic proxies, including the subfossil remains of chironomid larvae (Diptera, Chironomidae) (Luoto and Sarmaja-Korjonen, 2011; Engels et al., 2016; Wang et al., 2016).

Chironomid larvae are abundant and widespread in freshwater ecosystems (Cranston, 1995). The presence and abundance of the different species vary spatially relative to within-lake environmental gradients (Kurek and Cwynar, 2008), with water depth being among the most important (Heiri, 2004; Kurek and Cwynar, 2008; Luoto, 2010; Engels and Cwynar, 2011; Luoto, 2011; Cwynar et al., 2012). The strong relationship between chironomid assemblages and water depth changes was confirmed by multi-lake studies (Korhola et al., 2000; Barley et al., 2006; Luoto, 2009). The response of chironomids to water depth changes is commonly threshold-like (Engels and Cwynar, 2011). The parts of the depth gradient lacking noticeable turnover are followed by those revealing abrupt changes (i.e., thresholds) in the faunal assemblages. Engels and Cwynar (2011) found one to two such faunal thresholds in shallow lakes. Relationships between individual taxa and water depth are variable; some taxa (e.g., Corynoneura arcticatype, Psectrocladius sordidellus-type and Tanytarsus lugens-type) are known to be strongly affected by water depth (Engels and Cwynar, 2011; Luoto, 2011), whereas others (e.g., Cricotopus cylindraceus-type, Chironomus 
plumosus-type and Parachironomus varus-type) seem to be largely independent of it (Nazarova et al., 2010; Engels and Cwynar, 2011; Luoto, 2011). Based on his study of shallow Alpine and boreal lakes, Luoto (2012) suggested that depth optima of many taxa are uniform in different lakes despite contrasting lake characteristics.

Despite generally strong chironomid-water depth relationships, water depth does not have a direct influence on chironomids (Engels and Cwynar, 2011; Luoto, 2011; Velle et al., 2012). It might affect chironomids, mainly together and/or through temperature and oxygen concentration changes, presence/absence of aquatic macrophytes, and food quality and availability (Langdon et al., 2010). Despite the non-direct relationship between chironomids and water depth, lake level reconstructions based on subfossil chironomids may still be reliable, but such interpretations require additional assumptions. These assumptions are based on ecologically important determinants being monotonically related to water depth, subfossil assemblages that are not homogenized by taphonomic processes, and other environmental variables that do not override the effect of water level fluctuations on chironomid assemblages (Birks, 2010). Although all these assumptions might be violated (Velle et al., 2012), the reliability of chironomid-based water level reconstruction in a shallow lake has been demonstrated by Engels et al. (2012), who found a general agreement between palaeohydrological records obtained from chironomids and other, independent palaeohydrological proxies.

In this study, we present the distribution of subfossil chironomids in surface sediments along a water depth gradient within Lake Spore, northern Poland. Our aims were i) to determine how the subfossil chironomid assemblages change with water depth, ii) to estimate whether the water depth-chironomid relationship can be observed along the whole water depth gradient, and iii) to compare the water depth optima of dominant chironomid taxa in Lake Spore with the water depth optima of these taxa from other shallow lakes. Based on our results, we also aimed to evaluate the usefulness of subfossil chironomids for reconstruction of past water depth fluctuations in Lake Spore.

\section{METHODS}

\section{Study site}

Lake Spore is located in northern Poland (Fig. 1), within the extent of the Weichselian ice sheet, which retreated from this area after $16 \mathrm{ka}$ BP (Marks, 2012). Therefore, morphology of the area is of glacial origin, including numerous lakes and sandurs (i.e., outwash plains formed by meltwater from the ice sheet). The catchment area of Lake Spore is approximately 527 ha, and it is situated within the altitude range of 138 and 162 $\mathrm{m}$ asl. Surface sediments of the lake catchment consist mainly of glacio-fluvial sands, and only a small area adjacent to the eastern part of the lake is covered with peat deposits. The lake is surrounded by forests dominated by Pinus silvestris L., 1758, and at the eastern shore of the lake, on the peat deposits, by Alnus glutinosa (L.) Geartn., 1791. The only exception is the western shore of the lake, where a village is located, and the surrounding area is cultivated. The total annual precipitation in the area averages at $637 \mathrm{~mm}$. The July and January mean temperatures are 18.1 and $-4.7^{\circ} \mathrm{C}$, respectively (https://pl.climate-data.org/).

Lake Spore covers an area of approximately 85 ha, and it is a shallow lake with maximum water depth of approximately $7 \mathrm{~m}$ located in the eastern part of the lake basin (the coordinates for the deepest point of the lake are $53^{\circ} 47^{\prime} 51^{\prime \prime} \mathrm{N}$ and $16^{\circ} 43^{\prime} 38^{\prime \prime}$ E; Fig. 1 C,D). Lake Spore has a single, small inflow from the east and a single, small outflow that drains the lake towards the west (Fig. 1C). The influence of the inflow on the investigated chironomid assemblages should not be considerable because of its low discharge and its distant location (over $350 \mathrm{~m}$ ) from the nearest sampling site.

This study was designed to provide support for the reconstruction of Lake Spore past water level fluctuations which is conducted as a part of the research project focused on palaeohydrological changes in northern Poland. Selection of the study site was motivated by the characteristics that according to Dearing (1997) make it suitable for lake-level studies, namely small catchmentto-lake ratio $(\sim 6: 1)$ and shallow depth. The former feature ensures that hydrology of the lake is dominated by groundwater flow what usually results in marked longterm water-level fluctuations (Vassiljev, 1998). The shallow depth, in turn, is commonly regarded as a feature that favours more pronounced sedimentary record of the changes in water depth.

\section{Fieldwork}

Thirty-five surface sediment samples (the topmost 1 $\mathrm{cm}$ of the sediment) were taken from the eastern basin of Lake Spore on 9 August 2017 using an Ekman Grab (AMS 445.11, dimensions 15x15x15 cm) (Fig. 1 C,D). The samples were taken along a water depth gradient (from 0.4 to $6.4 \mathrm{~m}$ ), from five parallel transects (seven samples from each transect; Fig. 1D). Additionally, one sample was taken from the top of the sediment core drilled on 10 September 2017 using a UWITEC gravity corer (with a diameter of $90 \mathrm{~mm}$ ) from the deepest point of the lake that is located in line with the transect no. 3 (Fig. 1D). Applying this sampling design, small and approximately equally spaced intervals of sampling were maintained (Fig. 1D). Our aim with this sampling design was to keep 
other environmental variables independent of the water depth and constant, therefore focusing on an undisturbed relationship between subfossil chironomids and water depth. A Garmin GPSMAP 64S was used to mark the location of the sampling sites. Water depth at the sampling sites was measured with an Hondex PS-7 portable handheld depth sounder. Macrophyte coverage and composition were surveyed on 19 September 2018 at the selected sampling sites over the full water depth gradient. Moreover, the basic physico-chemical parameters of water, including the water temperature, dissolved oxygen concentration, electrolytic conductivity and $\mathrm{pH}$, were measured in the vertical profile at $1 \mathrm{~m}$ intervals between 0 and $6 \mathrm{~m}$ water depth and at the sediment/water interface (at $6.5 \mathrm{~m}$ ), using a YSI Professional Plus multiprobe. The measurements were carried out approximately $25 \mathrm{~m}$ to the south-west of the coring site, on 7 August 2017, 10 September 2017 and 19 September 2018.

\section{Laboratory techniques}

Samples consisting of 0.07-24.3 $\mathrm{g}$ of freeze-dried sediments were processed by deflocculation in warm $10 \%$ $\mathrm{KOH}$ solution for $20 \mathrm{~min}$ and then washed through a nylon sieve with $100 \mu \mathrm{m}$ mesh size. Head capsules of subfossil chironomids were sorted from the residue using a stereomicroscope under 40x magnification and then the chironomid remains were mounted onto microscopic slides using HydroMatrix ${ }^{\circledR}$. Identification was performed at $100 x-$ 400x magnification using the identification guides of Brooks et al. (2007), with reference to Wiederholm (1983) and Rieradeval and Brooks (2001). Microscopic slides are deposited in the Faculty of Geographical and Geological Sciences, Adam Mickiewicz University in Poznań.

Most samples contained at least 50 identifiable head capsules recommended for numerical analysis (Heiri and Lotter, 2001). Only three samples (sample 31, 51 and 32) contained fewer head capsules ( 45,40 and 48 , respectively)

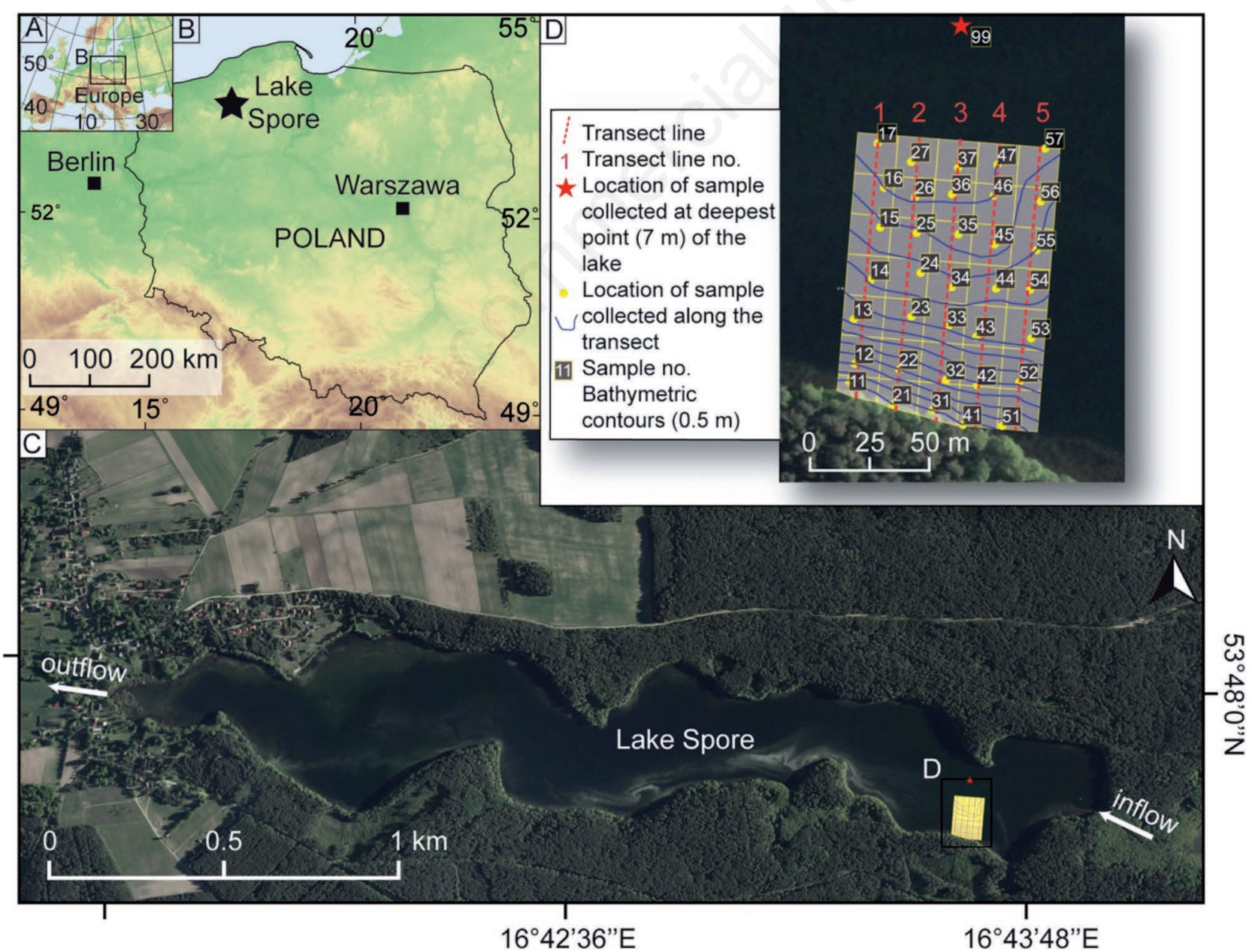

Fig. 1. Location of Lake Spore within Poland (A,B), the orthophoto of the lake and its surroundings with the study site (C), and the location of the sampling sites within the study area (D). 
than required; however, these samples were also included in the numerical analyses. The concentration of chironomid head capsules was calculated as the number of head capsules per gram of freeze-dried sediment. Loss-onignition (LOI) was measured at $550^{\circ} \mathrm{C}$ for each sediment sample according to the methodology by Heiri et al. (2001) to estimate the sediment organic matter content.

\section{Numerical analysis}

Square root-transformed relative abundance data of selected chironomid taxa (reaching at least $2 \%$ relative abundance and occurring at least in two samples) were used for statistical analyses. The Hill's N2 was calculated as a measure of effective number of occurrences of the taxa (Hill, 1973). The amount of compositional turnover in the data set was determined using detrended correspondence analysis (DCA). The results of the DCA showed that the gradient length of the first axis was less than two standard deviation units (SD units), suggesting that linear techniques are the most appropriate for this data set (Lepš and Šmilauer, 2003). Thus, principal component analysis (PCA) was run to visualize the distribution of chironomids; and redundancy analysis (RDA) was used based on the chironomid data against water depth as the sole constraining variable to examine the amount of variation in the chironomid assemblage explained by water depth. A significance level of the RDA result was assessed by Monte Carlo permutation test (999 permutations).

To determine the water depths at which significant compositional turnover of the chironomid assemblage occurred (if any), we applied a depth-constrained cluster analysis (CONISS). This method constrains the clustering algorithm so that the resulting dendrogram joins only those chironomid assemblages that are adjacent by lake depth. The number of significant zones of chironomids was assessed by the broken stick model (Bennett, 1996).

A relative abundance of dominant chironomid taxa (occurring in at least 7 samples) was modelled as a response to water depth using generalized linear models (GLMs) with quasi-Binomial link function. The model was set to a quadratic degree. Water depth optima and tolerances of the same taxa were calculated using weighted averaging (WA).

All computations were performed using $\mathrm{R}$ ver. 3.5.1. (R Core Team, 2018). We used the rioja package version 0.915.1 (Juggins, 2017) for plotting the diagram, calculating the Hill's N2 and CONISS analysis while ordinations were run with the vegan package ver. 2.5-2 (Oksanen et al., 2018).

\section{RESULTS}

\section{Characteristics of the sampling area}

The physico-chemical parameters of the lake water were generally constant down to $6 \mathrm{~m}$ depth during all three field campaigns and shifted at the water/sediment interface (6.5 m; Fig. 2). According to the measurements, Lake Spore has well-oxygenated (concentration of oxygen is mainly between 3 and $\left.8.9 \mathrm{mg} \mathrm{L}^{-1}\right)$ and alkaline $(\mathrm{pH}$ in the range 7.9-8.4) waters with a relatively low concentration of dissolved inorganic substances, as indicated by low conductivity values (not exceeding $199 \mu \mathrm{S} \mathrm{cm}^{-1}$ ).

The sampling area has simple bathymetry, with slightly increasing water depth from the lake shore towards the centre of the lake basin (Fig. 1D). The results of the LOI analysis show that the surface sediment organic matter content vary notably (Fig. 3). Between 0.4 and $1.5 \mathrm{~m}$ water depth (sampling points $11,21,31,51$ and 12), low organic matter content (1-4\%) and sandy substrate prevailed. However, at sampling point 41 (at 0.5 $\mathrm{m}$ water depth), organic matter (mainly terrestrial) was abundant, and LOI reached $90 \%$. At sampling points located between 2 and $3.7 \mathrm{~m}$ water depth (sampling points $22,32,42,52$ and 13), the organic matter content increased notably and reached $63 \%$, whereas below 3.7 $\mathrm{m}$ water depth LOI decreased again and varied between 23 and $49 \%$.

Macrophyte coverage and composition changed along depth gradient within the sampling area. The shallowest part ( $\leq 1.2 \mathrm{~m}$ water depth) was covered by Phragmites australis (Cav.) Steud., 1841, (sampling points 31, 41 and 51), with fewer occurrences of Ceratophyllum demersum L., 1753, and Elodea canadensis Michaux, 1803, (sampling points 11 and 21). Between 2 and $3.7 \mathrm{~m}$ water depth, only E. canadensis was found in a discontinuous cover, whereas below $3.7 \mathrm{~m}$ water depth macrophytes occurred sporadically or were absent.

\section{Distribution of the subfossil chironomid assemblages}

Altogether, 70 chironomid taxa (belonging to 4 subfamilies) were identified, of which 16 were found in fewer than two samples and/or had a relative abundance lower than $2 \%$. The distributions of the most abundant taxa are shown in Fig. 3. A number of taxa present in individual samples varied, mainly between 20 and 30, without a clear relation to depth. However, samples from shallow sites 11, 41, 51 and 32 (water depths $0.4,0.5,0.7$ and $2.3 \mathrm{~m}$, respectively) contained fewer taxa (between 15 and 19), whereas in those samples from greater water depths, 13, 54, 56, 15 and 46 (water depths 3.7, 4.6, 5.1, 5.4 and $6 \mathrm{~m}$, respectively) taxa were more abundant (between 31 and 37). None of the taxa occurred in all the samples, although Tanytarsus mendax-type, Tanytarsus pallidicornis-type and Psectrocladius sordidellus-type were present in 34 samples. The most abundant taxa were T. mendax-type, Corynocera ambigua Zetterstedt, 1837, and Cladotanytarsus mancustype (with mean relative abundances of 13.5, 7.1 and 6.9\%, respectively). Very low chironomid head capsule concentrations $\left(<24 \mathrm{hc} \mathrm{g}^{-1}\right)$ were found in the samples 
located between 0 and $1.5 \mathrm{~m}$ water depth, whereas between water depths of 1.5 and $4 \mathrm{~m}$, the chironomid concentration increased and ranged between 458 and $927 \mathrm{hc} \mathrm{g}^{-1}$, coinciding with increasing LOI values. The highest chironomid concentration (up to $1580 \mathrm{hc} \mathrm{g}^{-1}$ ) was found in the samples located below $4 \mathrm{~m}$ water depth.

Generally, two significant chironomid zones were indicated by CONISS with a faunal threshold at 2.6-3.7 $\mathrm{m}$ (Fig. 3). Two non-significant sub-zones were found for the first zone (S1, 0.4-2.6 m water depth). The S1-a subzone (0.4-0.7 $\mathrm{m}$ water depth) was dominated by Corynoneura arctica-type, whereas in the S1-b sub-zone (1.5-2.6 water depth), Dicrotendipes nervosus-type, Psectrocladius sordidellus-type and T. pallidicornis-type dominated and Ablabesmyia and Pseudochironomus occurred in small but stable relative abundances as well (Fig. 3). The taxonomic composition of second zone (S2, 3.7-7 m water depth) was less variable compared to $\mathrm{S} 1$ zone; however, two non-significant sub-zones were indicated by CONISS. The S2-a sub-zone (3.7-4.3 m water depth) was dominated by the $T$. mendax-type and C. mancus-type, whereas in the S2-b sub-zone (4.6-7 m water depth), C. ambigua became dominant next to the $T$. mendax-type, and the relative abundances of $C$. mancustype fluctuated (Fig. 3).
PCA analysis also confirmed a clear distinction of the $\mathrm{S} 1$ and S2 zones, as well as revealing the samples of S1 zone to be much more variable than the samples of the S2 zone (Fig. 4). Site scores of the S1 zone had negative values on the first PCA axis, whereas site scores of the S2 zone had mainly positive values on the same PCA axis, and on the second PCA axis they ranged between -1 and 0.5 units.

The RDA explained the predictors of the distribution of the chironomid assemblages in the following way: it is strongly related to water depth with a level of statistical significance $\mathrm{P}<0.001$, and the variance was explained by $25.12 \%$ of the species data.

The GLM analysis revealed that, out of 44 dominant taxa (present in at least 7 samples), 12 have significant relationships with water depth (Fig. 5). The WA optima of these taxa were within the range of 2.2-5.2 m water depth (Fig. 6). Of the more abundant taxa (N2>10), Limnophyes, T. glabrescens-type and $C$. arctica-type were most restricted to the shallow lake littoral zone (between ca. 1-3 $\mathrm{m})$, whereas C. ambigua, Paratanytarsus penicillatus-type, Polypedilum sordens-type and Cladopelma lateralis-type had higher water depth optima (between approximately 3 and $5 \mathrm{~m})$. The WA tolerances of taxa with greater water depth optima were generally narrow $(\sim 1.5 \mathrm{~m} v s>2 \mathrm{~m}$ of taxa restricted to smaller water depths).

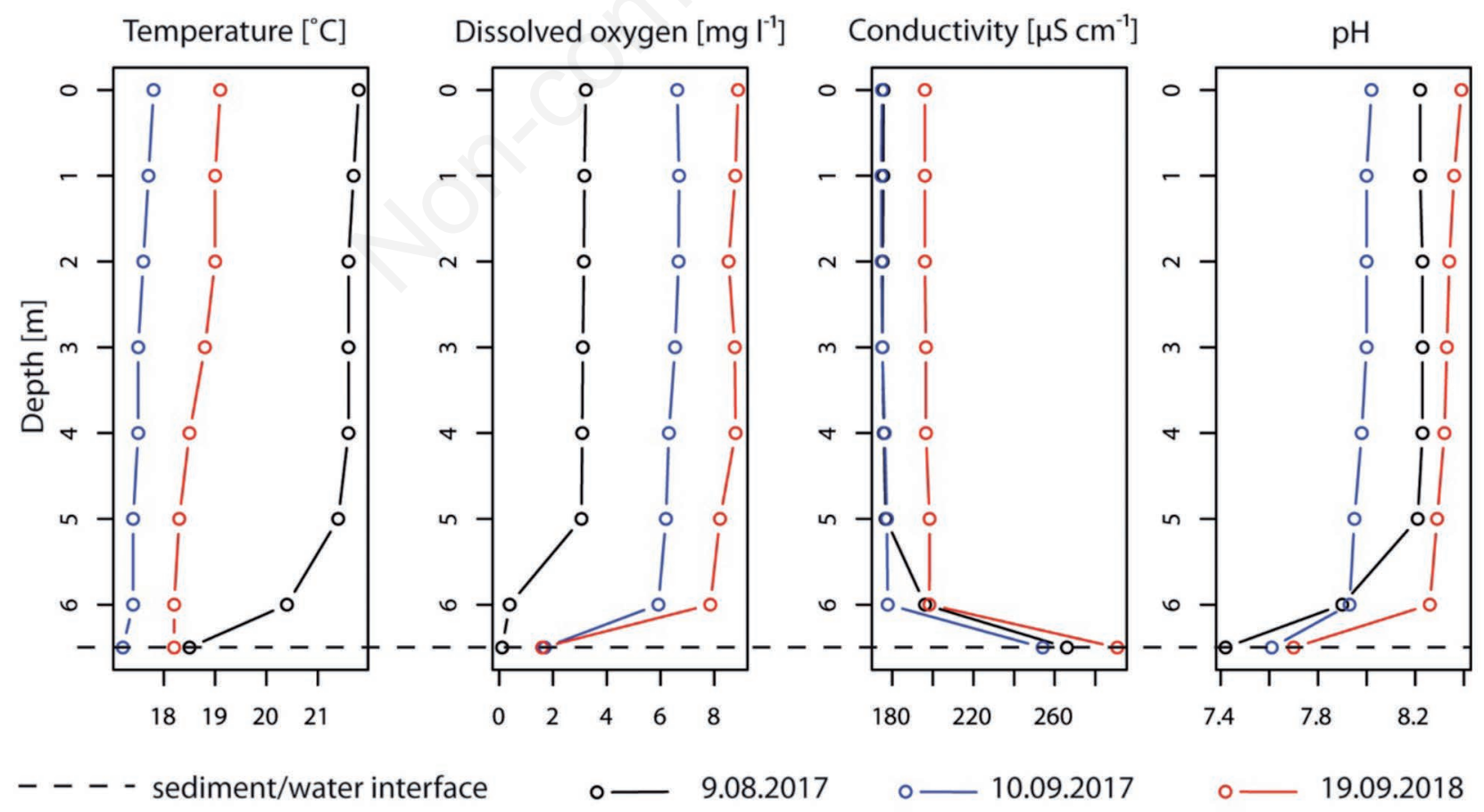

Fig. 2. Physico-chemical parameters of Lake Spore water measured directly in the vertical profile at $1 \mathrm{~m}$ intervals to a depth of $6 \mathrm{~m}$ and at sediment/water interface (6.5 $\mathrm{m}$ water depth). 


\section{DISCUSSION}

\section{Relationship of chironomid assemblages with water depth}

Chironomid assemblages in Lake Spore tended to be dominated by the same taxa throughout a water depth gradient but with varying percentage of abundance. This is consistent with the results of a study of five Norwegian lakes conducted by Heiri (2004) and with the findings of (Engels and Cwynar, 2011) who showed that species richness in shallow lakes is uniform irrespective of the water depth. The presence of taxa characteristic of the shallow littoral zone of Lake Spore (e.g., Corynoneura arctica-type, Psectrocladius spp., and Limnophyes) at greater water depths can point to the redeposition of head capsules towards the lake centre. This process also explains the slightly higher number of species encountered in some samples from deeper sites in comparison to the samples from shallower sites within the lake. However, noticeably variation in percentage abundance of individual taxa in Lake Spore suggest that the fossil assemblages are derived mainly from larvae that lived close to the sampling location. Many other studies found that chironomid assemblages vary across a lake's basin ( Heiri, 2004; Luoto, 2010, 2011; Engels and Cwynar, 2011). However, opposite results (Brodersen and Lindegaard, 1999; Van Hardenbroek et al., 2010) also have been reported.

Water depth in our data is an important variable that explains $25.12 \%$ of the variance in chironomid assemblages. This result fits well with the range of 9 and $34 \%$ of explained variances reported in other shallow lakes (Heiri, 2004; Eggermont et al., 2007; Kurek and Cwynar, 2008; Luoto, 2010; Engels and Cwynar, 2011; Luoto, 2011; Cwynar et al., 2012; Velle et al., 2012). Despite the overall strong chironomid-water depth relationship, the sensitivity of our chironomid fauna towards water depth changes does not show a continuous response along the entire depth gradient. The most abrupt assemblage change occurred at 2.6-3.7 $\mathrm{m}$ water depth in Lake Spore; however, two less-prominent changes were also noted at 0.7-1.5 and 4.3-4.6 $\mathrm{m}$ water depth. Generally, the taxonomic composition of midges varied noticeably between zones (i.e., below $2.6 \mathrm{~m}$ and above $3.7 \mathrm{~m}$ water depth), whereas within zones, the

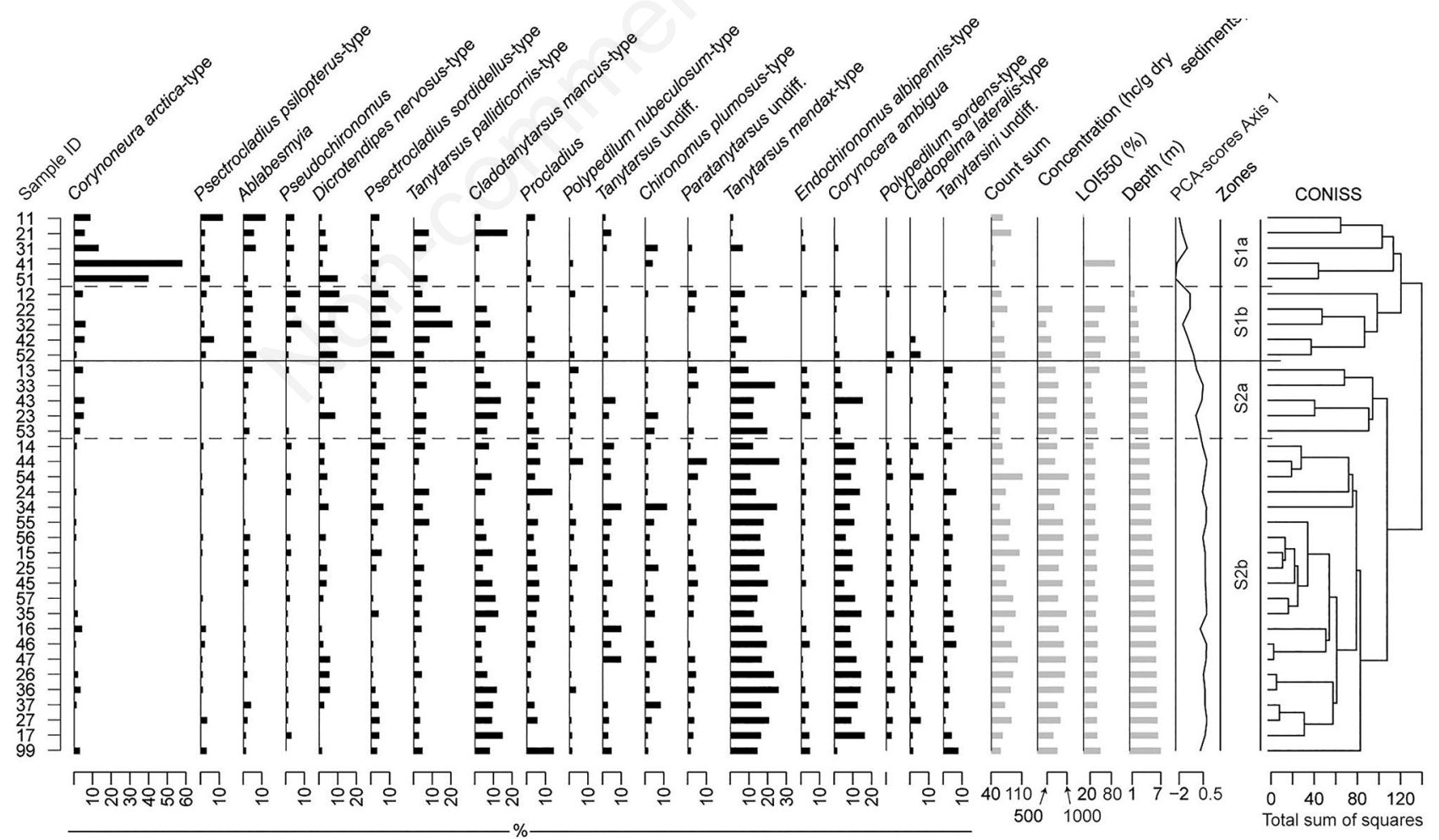

Fig. 3. Sample characteristics (percent abundance of the most abundant chironomid taxa, count sums, head capsules concentrations, and LOI and PCA-scores of axis 1). Samples are arranged according to increasing depth. Chironomid zones were derived based on depth constrained cluster analysis (CONISS). Taxa are ordered according to their depth optima, which were calculated using weighted averaging (WA), with the shallow water taxa to the left. 
assemblages were relatively homogenous, except in the shallow littoral samples (water depth between 0.4-1.5 m), where the chironomid fauna showed high heterogeneity. This heterogeneity was likely related to the observed high variability of substrata and/or more diverse environmental conditions compared with the deeper parts of the lake. Engels and Cwynar (2011) found abrupt changes in chironomid assemblages at similar water depths (at 1-2 and 5-7 $\mathrm{m}$ water depths) along a depth gradient (i.e., faunal thresholds) in shallow lakes; however, they could not distinguish the driving factor of this phenomenon. Lake Spore is a polymictic lake, as revealed by uniform physicochemical conditions along the water column during the summer seasons (Fig. 2). Thus, the oxygen concentration, the water temperature and the $\mathrm{pH}$ of the water column did not change notably and therefore could not influence strongly the distribution of chironomids. Organic matter content (LOI) does not change markedly at the threshold depth; thus, it is unlikely to be a driving factor of faunal overturning as well. We cannot exclude that differences in species composition of the macrophyte assemblages and macrophyte coverage of the lake bottom could cause some changes in the chironomid assemblage (Brodersen et al., 2001). This is suggested by the proximity of the depth of the faunal threshold and the depth where macrophytes become less dense and finally disappear. However, our macrophyte survey was conducted only in selected sampling points and only once; thus, detailed interpretation of the impact of macrophytes on the distribution of chironomids is not possible. Although it is not clear which environmental factor(s)

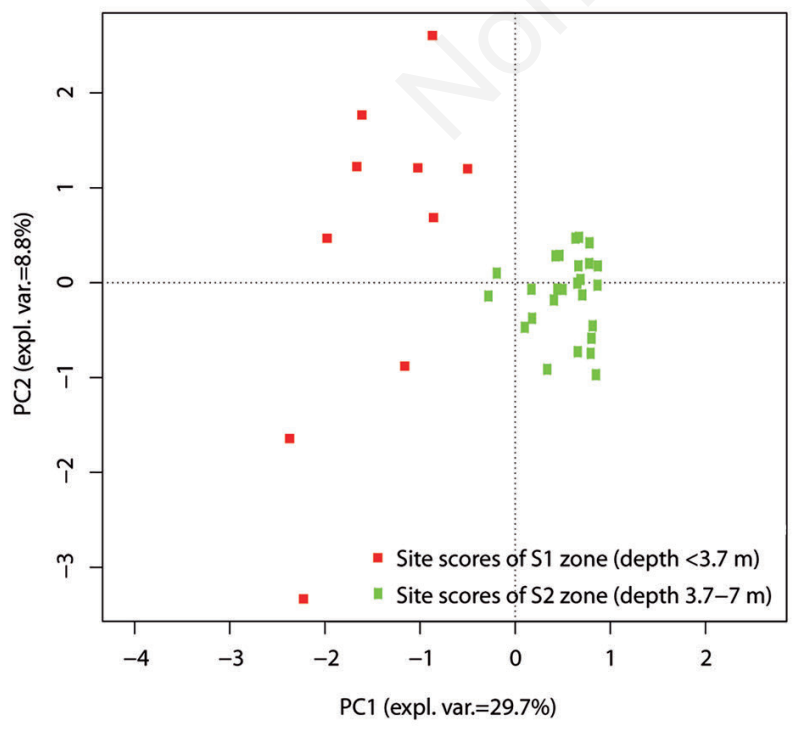

Fig. 4. Principal component analysis (PCA) biplot showing distribution of Lake Spore chironomid communities. could cause the faunal threshold at a certain water depth in Lake Spore, its presence appears to be crucial to the observed strong chironomid-water depth relationship in this lake.

\section{Relationship of individual chironomid taxa with water depth}

Using GLMs, we found that $12(27 \%)$ dominant chironomid taxa in Lake Spore were significantly related to water depth (Fig. 5). These taxa include Chironomus anthracinus-type, Polypedilum nubeculosum-type, T. mendax-type and $P$. sordidellus-type, which have also significant relationships with the water depth according to the study of Engels and Cwynar (2011). The Cricotopus cylindraceus-type and Chironomus plumosus-type were also abundant in Lake Spore but did not show significant relations to water depth in accordance with other studies (Nazarova et al., 2010; Luoto, 2011). However, we did not find a clear relationship with the water depth of Cladopelma lateralis-type, Paratanytarsus penicillatus-type, Corynoneura arctica-type, Procladius, T. lugens-type, $T$. glabrescens-type, Ablabesmyia, Lauterboniella or Microtendipes pedellus-type, taxa that were important indicators of water depth changes in other studies (Eggermont et al., 2007; Luoto, 2009; Nazarova et al., 2010; Engels and Cwynar, 2011; Cwynar et al., 2012). T. pallidicornis-type was reported by Engels and Cwynar (2011) as not being related to water depth, which was contrary to our results. Differences between our and previously published studies can be explained by the differences in the depth gradients covered (ranging from 5.6 to $11.6 \mathrm{~m}$ ) and in limnological and environmental conditions (e.g., trophic status, alkalinity, and climate). Taxonomic variances must also be included since some of the mutual chironomid taxa (species morphotypes) likely include different species in different regions (see Eggermont et al., 2007; Luoto, 2009; Nazarova et al., 2010; Engels and Cwynar, 2011; Cwynar et al., 2012). Nevertheless, all of these studies reported a high contribution of chironomid taxa (29-75\%) that are significantly related to water depth, suggesting that chironomids are generally sensitive indicators of water depth changes in shallow lakes. However, local environmental conditions influencing the sensitivity of individual taxa against water depth changes cannot be excluded.

We aimed to compare the water depth optima and tolerances of the dominant chironomid taxa of Lake Spore with those found in other studies that covered roughly the same depth gradient as in our study. Therefore, we compared our results with surveys from Lake Moaralmsee (max depth=7 m; Luoto, 2011), Lake Pieni-Kauro (max depth=7.9 m; Luoto, 2010), and with a multi-lake ( $\mathrm{n}=64)$ survey from Finland (sampled depths range from 0.7 to 7 m; Luoto, 2009) (Fig. 6). The 17 dominant taxa preferring 
water depths above $4.4 \mathrm{~m}$ in Lake Spore (i.e., Limnophyes, Lauterborniella, T. glabrescens-type, $C$. arctica-type, T. lactescens-type, P. psilopterus-type, Ablabesmyia, Pseudochironomini, Parachironomus varus-type, D. nervosus-type, Nanocladius rectinervistype, P. sordidellus-type, Eukieferiella undiff., $T$. pallidicornis-type, Stictochironomus rosenschoeldi-type, Chironomus anthracinus-type and C. cylindraceus-type) have water depth optima similar to those presented in other studies (Luoto, 2009, 2010, 2011), although, some variation was noted as well (Fig. 6). In the literature (Brooks et al., 2007), these taxa are described as
Limnophyes sp.

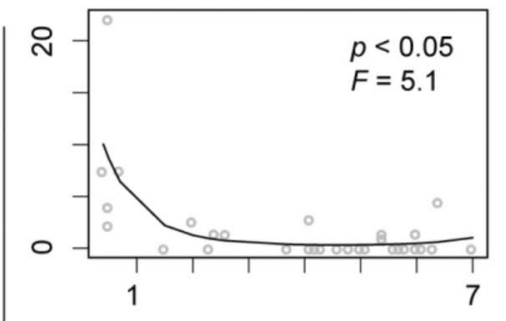

Dicrotendipes nervosus-type
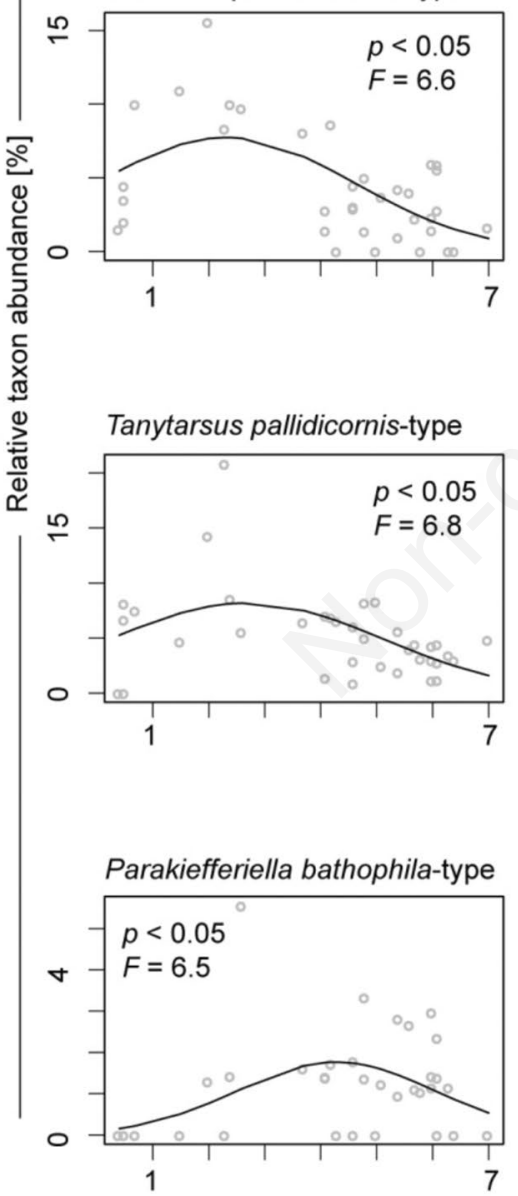

Tanytarsus lactascens-type

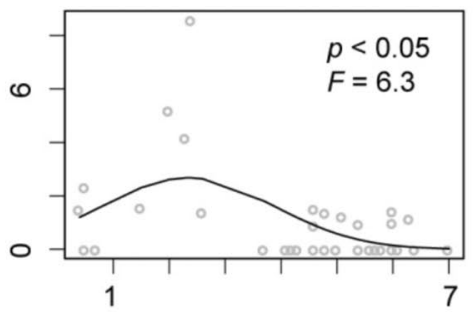

Psectrocladius sordidellus-type

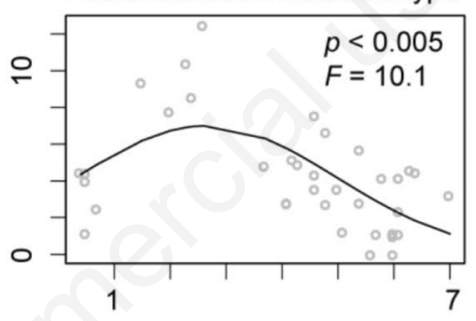

Chironomus anthracinus-type

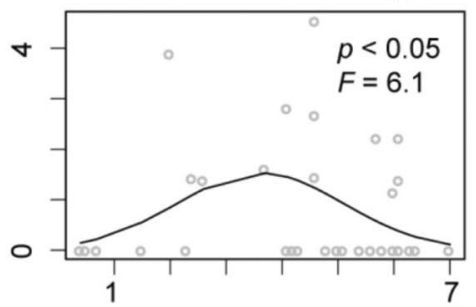

Tanytarsus mendax-type

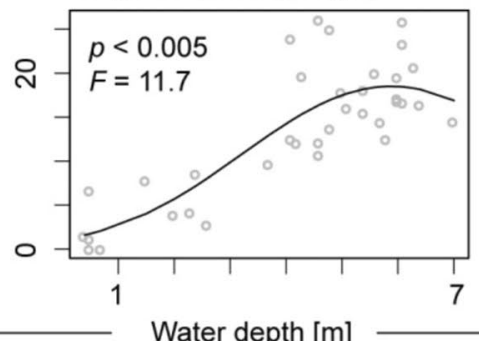

Psectrocladius psilopterus-type

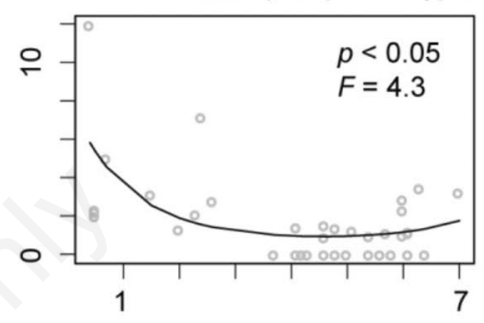

Eukiefferiella undiff.

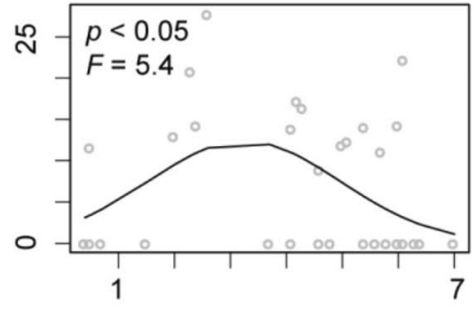

Polypedilum nubeculosum-type
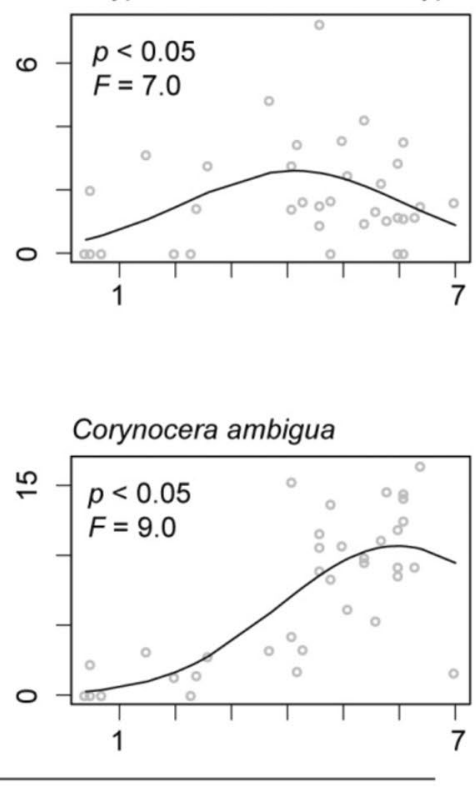

Fig. 5. Taxa response curves (generalized linear models; GLMs) to water depth for the taxa revealing significant relationship (P<0.05) with water depth in Lake Spore. Level of statistical significance $(\mathrm{P})$ and $\mathrm{F}$ statistics $(\mathrm{F})$ for testing model significance relative to null model are given for these taxa. 


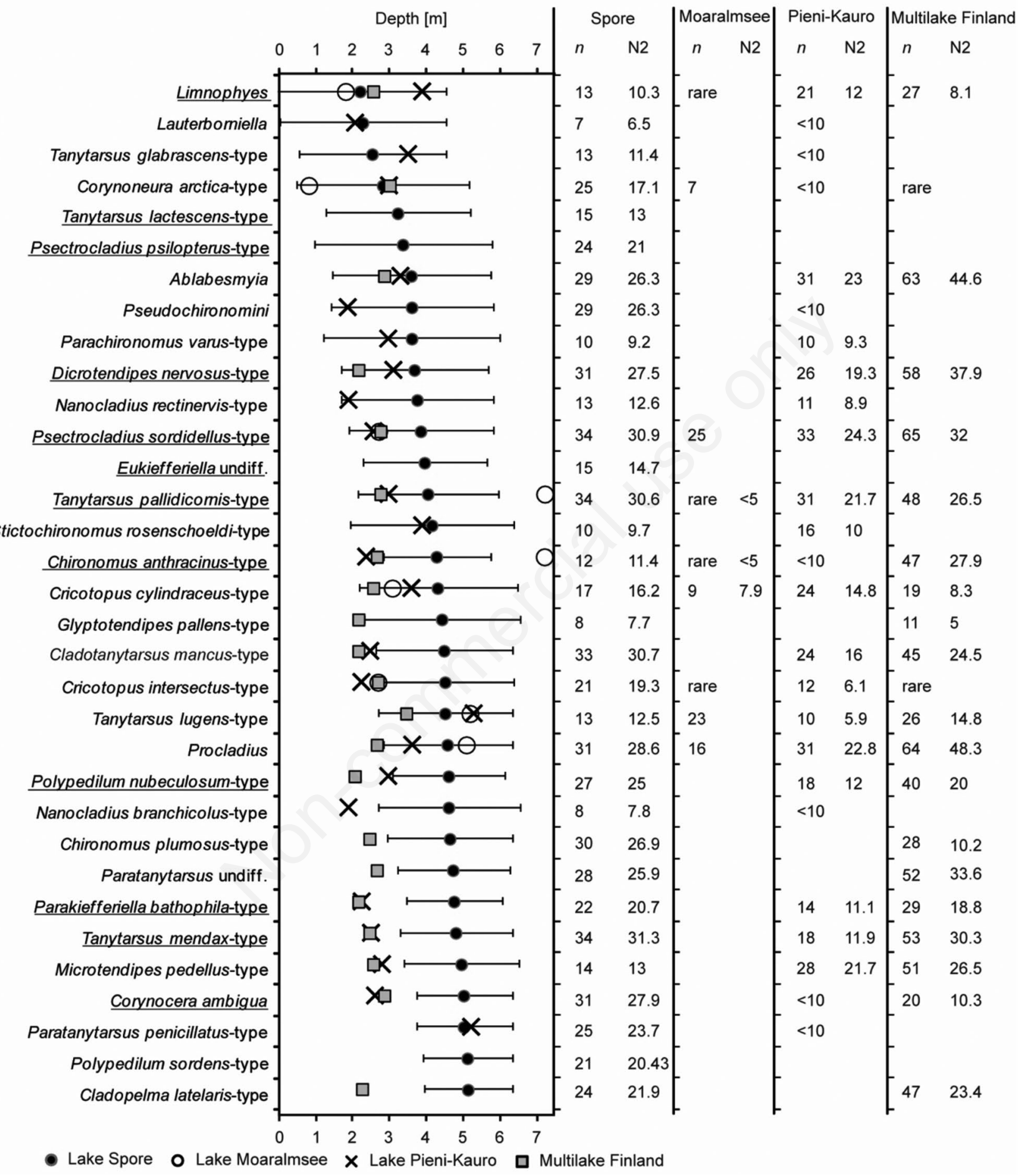

Fig. 6. Estimated weighted-averaging (WA) water depth optima and tolerances ("error" bars) of dominant chironomid taxa in Lake Spore. Taxa revealing a significant relationship $(\mathrm{P}<0.05)$ with water depth according to generalized linear models $(\mathrm{GLMs})$ are underlined. Taxa optima estimated using similar depth gradients and WA method from three other studies [Lake Moaralmsee, Austrian Alps (Luto, 2011); Lake Pieni-Kauro, Eastern Finland (Luoto, 2010); and multi-lake ( $\mathrm{n}=64)$ survey from Finland (Luoto, 2009)] are provided for comparison. When not available from original publication, data were taken from Luoto (2012). Information on the number of occurrences (n) and the Hill's N2 (N2) as a measure of effective number of occurrences of the taxa is provided next to the chart. 
inhabitants of the littoral zone, except for the $C$. anthracinus-type that was reported as preferring deeper parts of the lakes (Heiri, 2004; Engels and Cwynar, 2011). Depth tolerances of the taxa inhabiting depths above 4.4 $\mathrm{m}$ in Lake Spore are noticeably wider in comparison with those found in other studies, as shown in Fig. $6(>2 v s$ $\sim 1.5 \mathrm{~m}$ ). This might suggest that the downslope transport of head capsules plays an important role in Lake Spore.

Of the 17 dominant taxa preferring water depths below $4.4 \mathrm{~m}$ in Lake Spore (Glyptotendipes pallens-type, Cladotanytarsus mancus-type, Cricotopus intersectustype, Procladius, Polypedilum nubeculosum-type, Nanocladius branchicolus-type, C. plumosus-type, Paratanytarsus undiff., Parakiefferiella bathophila-type, T. mendax-type, Microtendipes pedellus-type, Corynocera ambigua, $P$. penicillatus-type, $P$. sordens-type, Cladopelma lateralis-type, Tanytarsini undiff.) only $T$. lugens, Procladius and C. plumosus-type were reported previously as common profundal inhabitants, whereas the remaining taxa are associated with the lake's littoral zone (Brooks et al., 2007). Domination of the littoral taxa in the deepest part of Lake Spore likely results from its polymictic nature, which ensures unification of the physico-chemical conditions within the lake column. In most instances, taxa preferring water depths below $4.4 \mathrm{~m}$ have noticeably greater WA depth optima ( $>2 \mathrm{~m}$ for most of the taxa) compared with the results of Luoto's studies (2009, 2010, 2011) (Fig. 6). The most likely explanation is that, next to the water depth, other environmental factors could influence the distribution of the chironomid assemblages in Lake Spore in comparison with other sites (Luoto, 2009, 2010, 2011). However, this assumption is contradictory to Luoto (2012), who concluded that the water depth optima of chironomids in shallow lakes are spatially uniform despite differences in the lake's characteristic.

\section{Implications for chironomid-based reconstruction of Lake Spore past water level fluctuations}

Our results indicate changes in the chironomid assemblages along water depth gradient and a significant relationship between the presence of many taxa and changes in water depth. This is consistent with previous works (Eggermont et al., 2007; Engels and Cwynar, 2011; Luoto, 2011; Cwynar et al., 2012), making the chironomid remains potentially useful water level proxy in Lake Spore palaeolimnological studies. Even if the relationship of some taxa with water depth might not be observed, changes in the relative abundances of several taxa (on assemblage level) which reveal a significant relationship with water depth (Fig. 5) are likely reliable to infer water level changes. At the same time, inferences of the direction (i.e., increase $v s$ decrease of water level) are more likely than inferences of the amplitude of the reconstructed fluctuations. Taxa water depth optima appear to vary depending on a lake's conditions, as revealed by comparison of our results with works of Luoto $(2009,2010,2011)$ (Fig. 6). Thus, attempts to quantify water level changes from fossil assemblages based on depth optima estimated using modern assemblages might not be reliable.

We did not find any noticeable chironomid assemblage turnover below $4.6 \mathrm{~m}$ water depth. Thus, we should not expect that subfossil chironomid analysis of the sediment core taken from the deepest part of the lake $(7 \mathrm{~m})$ will allow for the reconstruction of subtle water level changes. This is consistent with the conclusion of Walker et al. (2003) that only major water level variations are likely to be reliably inferred from subfossil chironomids. At the same time, Dietze et al. (2016) showed that the absolute amplitude of lake levels in EastCentral Europe could be as high as $\sim 8 \mathrm{~m}$ for the Holocene. However, most fluctuations probably did not exceed $3 \mathrm{~m}$ (Dearing, 1997; Kowalewski, 2014). Instrumental data from Poland, covering the period 1976-2010, revealed that natural lake level variations during this period were generally smaller than $1 \mathrm{~m}$ (Wrzesiński and Ptak, 2016). In this light, we suggest that subfossil chironomid analysis might be used only for the reconstruction of major Holocene water level fluctuations in Lake Spore.

\section{CONCLUSIONS}

Our study of subfossil chironomids from the surface sediments of Lake Spore facilitates recognition of chironomid-water depth relationships in the lake and assessments of the lake specific utility of the chironomid fauna as a water depth proxy in palaeolimnological applications.

- Although the redeposition of chironomid head capsules was possible, the majority of the faunal remains were deposited close to the sampling location. Thus, past taphonomic processes will likely not markedly bias chironomid-based lake level reconstruction.

- Water depth is an important variable that explained $25.12 \%$ of the variance in chironomid assemblages. Of the abundant chironomid taxa, 27\% were significantly related to water depth. This strong relationship of the fauna with water depth suggests that chironomid distribution across the lake bottom could have been efficiently modified by the past water level fluctuations in the lake.

- Water depth optima of Lake Spore dominant chironomid taxa differ from the estimations performed for these taxa in other shallow lakes. This finding suggests that, next to the water depth, other environmental factors influence the distribution of the 
chironomid assemblages in Lake Spore and thus can potentially confound lake level inferences.

- The chironomid-water depth relationship varied along the water depth gradient. The most abrupt assemblage change occurred at 2.6-3.7 m water depth. We found macrophytes to be a possible environmental factor that caused the faunal threshold for those depths.

- Considering the rates of chironomid turnover along a depth gradient in Lake Spore and amplitude of lake level fluctuations in East-Central Europe, chironomidbased palaeolimnological studies will enable reliable reconstruction of major Holocene water level fluctuations in Lake Spore.

\section{ACKNOWLEDGMENTS}

The study was financed through a grant from the National Science Centre (NCN), Grant No. 2016/21/N/ ST10/00313. We would like to express our gratitude to Katarzyna Kajukało-Drygalska for her help during the fieldwork. KP wants to thank Stephen J. Brooks for introduction to subfossil chironomid analysis. We thank the two reviewers for comments that improved the quality of the manuscript.

\section{REFERENCES}

Barley EM, Walker IR, Kurek J, Cwynar LC, Mathewes RW, Gajewski K, Finney BP, 2006. A northwest North American training set: distribution of freshwater midges in relation to air temperature and lake depth. J. Paleolimnol. 36:295-314.

Bennett KD, 1996. Determination of the number of zones in a biostratigraphical sequence. New Phytol. 132:155-170.

Birks HJB, 2010. Strengths and weaknesses of quantitative climate reconstructions based on late-quaternary biological proxies. Open Ecol J3:68-110.

Brodersen KP, Lindegaard C, 1999. Classification, assessment and trophic reconstruction of Danish lakes using chironomids. Freshwater Biol. 42:143-157.

Brodersen KP, Odgaard BV, Vestergaard O, Anderson NJ, 2001. Chironomid stratigraphy in the shallow and eutrophic Lake Søbygaard, Denmark: chironomid-macrophyte cooccurrence. Freshwater Biol. 46:253-267.

Brooks SJ, Langdon PG, Heiri O, 2007. The identification and use of Palaearctic Chironomidae larvae in palaeoecology. Quaternary Research Association, London: $276 \mathrm{pp}$.

Coops H, Beklioglu M, Crisman TL, 2003. The role of waterlevel fluctuations in shallow lake ecosystems-workshop conclusions. Hydrobiologia 506:23-27.

Cranston P. 1995. Introduction to the Chironomidae, p. 1-7. In: P.D. Armitage, L.C. Pinder and P. Cranston (eds.), The Chironomidae: the biology and ecology of non-biting midges. Chapman \& Hall.

Cwynar LC, Rees ABH, Pedersen CR, Engels S, 2012. Depth distribution of chironomids and an evaluation of site-specific and regional lake-depth inference models: a good model gone bad? J. Paleolimnol. 48:517-533.

Dearing J, 1997. Sedimentary indicators of lake-level changes in the humid temperate zone: a critical review. J. Paleolimnol. 18:1-14.

Dietze E, Słowiński M, Zawiska I, Veh G, Brauer A, 2016. Multiple drivers of Holocene lake level changes at a lowland lake in northeastern Germany. Boreas 45:828-845.

Eggermont H, De Deyne P, Verschuren D, 2007. Spatial variability of chironomid death assemblages in the surface sediments of a fluctuating tropical lake (Lake Naivasha, Kenya). J. Paleolimnol. 38:309-328.

Engels S, Bakker MaJ, Bohncke SJP, Cerli C, Hoek WZ, Jansen B, Peters T, Renssen H, Sachse D, Van Aken JM, Van Den Bos V, Van Geel B, Van Oostrom R, Winkels T, Wolma M, 2016. Centennial-scale lake-level lowstand at Lake Uddelermeer (The Netherlands) indicates changes in moisture source region prior to the $2.8-\mathrm{kyr}$ event. Holocene 26:1075-1091.

Engels S, Cwynar LC, 2011. Changes in fossil chironomid remains along a depth gradient: evidence for common faunal thresholds within lakes. Hydrobiologia 665:15-38.

Engels S, Cwynar LC, Rees ABH, Shuman BN, 2012. Chironomid-based water depth reconstructions: an independent evaluation of site-specific and local inference models. J. Paleolimnol. 48:693-709.

Gałka M, Apolinarska K, 2014. Climate change, vegetation development, and lake level fluctuations in Lake Purwin (NE Poland) during the last $8600 \mathrm{cal}$. BP based on a highresolution plant macrofossil record and stable isotope data ( $\delta 13 \mathrm{C}$ and $\delta 180)$. Quatern. Int. 328-329:213-225.

Heiri O, 2004. Within-lake variability of subfossil chironomid assemblages in shallow Norwegian lakes. J. Paleolimnol. 32:67-84.

Heiri O, Lotter AF, 2001. Effect of low count sums on quantitative environmental reconstructions: an example using subfossil chironomids. J. Paleolimnol. 26:343-350.

Heiri O, Lotter AF, Lemcke G, 2001. Loss on ignition as a method for estimating organic and carbonate content in sediments: reproducibility and comparability of results. J. Paleolimnol. 25:101-110.

Hill MO, 1973. Diversity and evenness: a unifying notation and its consequences. Ecology 54:427-432.

Juggins S, 2017. rioja: Analysis of Quaternary Science Data, R package version 0.9-15.1.

Korhola A, Olander H, Blom T, 2000. Cladoceran and chironomid assemblages as quantitative indicators of water depth in subarctic Fennoscandian lakes. J. Paleolimnol. 24:43-54.

Kowalewski G, 2014. [Alogeniczne i autogeniczne składowe zarastania jezior-hipoteza wahań poziomu wody].[Article in Polish]. Studia Limnologica et Telmatologica Monographiae 1:1-196.

Kurek J, Cwynar LC, 2008. Effects of within-lake gradients on the distribution of fossil chironomids from maar lakes in western Alaska: implications for environmental reconstructions. Hydrobiologia 623:37-52.

Langdon PG, Ruiz ZOE, Wynne S, Sayer CD, Davidson TA, 2010. Ecological influences on larval chironomid communities in shallow lakes: implications for 
palaeolimnological interpretations. Freshwater Biol. 55:531545.

Lepš J, Šmilauer P. 2003. Multivariate analysis of ecological data using CANOCO. Cambridge University Press.

Luoto TP, 2009. A Finnish chironomid- and chaoborid-based inference model for reconstructing past lake levels. Quaternary Sci. Rev. 28:1481-1489.

Luoto TP, 2010. Hydrological change in lakes inferred from midge assemblages through use of an intralake calibration set. Ecol. Monogr. 80:303-329.

Luoto TP, 2011. Intra-lake patterns of aquatic insect and mite remains. J. Paleolimnol. 47:141-157.

Luoto TP, 2012. Spatial uniformity in depth optima of midges: evidence from sedimentary archives of shallow Alpine and boreal lakes. J. Limnol. 71:228-232. doi: 10.4081/jlimnol. 2012.e24.

Luoto TP, Sarmaja-Korjonen K, 2011. Midge-inferred Holocene effective moisture fluctuations in a subarctic lake, northern Lapland. Boreas 40:650-659.

Marks L, 2012. Timing of the Late Vistulian (Weichselian) glacial phases in Poland. Quaternary Sci. Rev. 44:81-88.

Nazarova L, Herzschuh U, Wetterich S, Kumke T, Pestryakova L, 2010. Chironomid-based inference models for estimating mean July air temperature and water depth from lakes in Yakutia, northeastern Russia. J. Paleolimnol. 45:57-71.

Oksanen J, Blanchet F, Friendly M, Kindt R, Legendre P, Mcglinn D, Minchin P, O’Hara R, Simpson G, Solymos P, Stevens H, Szoecs E, Wagner H. 2018. Vegan: Community Ecology Package. R package version 2.5-2.

R Core Team, 2018. R: A Language and Environment for Statistical Computing, R Foundation for Statistical
Computing, Austria. URL http://www.R-project.org.

Rieradeval M, Brooks SJ, 2001. An identification guide to subfossil Tanypodinae larvae (Insecta: Diptera: Chironomidae) based on cephalic setation. J. Paleolimnol. 25:81-99.

Van Hardenbroek M, Heiri O, Wilhelm MF, Lotter AF, 2010. How representative are subfossil assemblages of Chironomidae and common benthic invertebrates for the living fauna of Lake De Waay, the Netherlands? Aquat. Sci. 73:247-259.

Vassiljev J, 1998. The simulated response of lakes to changes in annual and seasonal precipitation: implication for Holocene lake-level changes in northern Europe. Clim. Dynam. 14:791-801.

Velle G, Telford RJ, Heiri O, Kurek J, Birks HJB, 2012. Testing intra-site transfer functions: an example using chironomids and water depth. J. Paleolimnol. 48:545-558.

Walker IR, Levesque A, Pienitz R, Smol JP, 2003. Freshwater midges of the Yukon and adjacent Northwest Territories: a new tool for reconstructing Beringian paleoenvironments? J. N. Am. Benthol. Soc. 22:323-337.

Wang H, Brooks SJ, Chen J, Hu Y, Wang Z, Liu J, Xu Q, Chen F, 2016. Response of chironomid assemblages to East Asian summer monsoon precipitation variability in northern China since the last deglaciation. J. Quaternary Sci. 31:967-982.

Wiederholm T, 1983. Chironomidae of the Holarctic Region. Keys and diagnoses. Part I. Larvae. Entomol. Scand. Suppl. 19:457.

Wrzesiński D, Ptak M, 2016. Water level changes in Polish lakes during 1976-2010. J. Geogr. Sci. 26:83-101. 